\title{
Partitioning of first row transition elements in mantle lithologies
}

\author{
OTTO LANG AND SARAH LAMBART \\ University of Utah \\ Presenting Author: sarah.lambart@utah.edu
}

First Row Transition Elements (FRTEs) have been identified as potential petrogenetic indicators because of their contrasted partitioning behaviors between the solid mantle phases. Using a combination of published data on natural and experimental samples and new high precision analyses (high-current microprobe and LA-ICP-MS analyses), we investigate the various parameters that control FRTE partitioning between common mantle minerals.

Our results show that mantle pyroxenites (found in ophiolites and ultramafic massifs) and peridotites share same mineralmineral exchange coefficients, $K d_{m n l l / m n l 2}$, independently of their compositions as well as their pressures and temperatures of equilibration. $\mathrm{Mn}$ preferentially partitions in garnet $\left(\mathrm{Kd}(\mathrm{Mn} / \mathrm{Fe})_{\mathrm{g} t / \mathrm{cpx}}=1.56 \pm 0.54\right)$ rather than in orthopyroxene and olivine $(0.699 \pm 0.152$ and $0.466 \pm 0.131$, respectively) in pyroxenites, with similar coefficient values for peridotites. On the contrary, $\mathrm{Zn}$ and $\mathrm{Ni}$ both preferentially partition in olivine rather than in clinopyroxene and garnet. $\mathrm{Ni}$ also shows a strong affinity with spinel $\left(K d(N i / M g)_{\mathrm{sp} / \mathrm{ol}} \sim 1.8-2.1\right)$, suggesting that even small proportions of spinel in mantle lithologies should be taken into account when modeling the partitioning behavior of Ni.

Preliminary observations on eclogites (i.e., rocks resulting from the metamorphism of the oceanic crust) and arclogites (i.e., mafic cumulates found as xenoliths in arc settings), however, show that they present distinctively higher $K d(\mathrm{Mn} / \mathrm{Fe})_{g t / c p x}$ and lower $\mathrm{Kd}(\mathrm{Zn} / \mathrm{Fe})_{g t / \mathrm{ppx}}$ than those in mantle lithologies, implying that convection and mixing into the asthenospheric mantle may significantly affect the partitioning behavior of FRTEs.

Finally, we tested if we could use FRTE ratios from basalt compositions to solve for modal proportions in the mantle source. We applied the $K d$ determined from mantle lithologies in this study, along with experimental melt-mineral partitioning coefficients and a simple batch melting model, on two series of basalts from Iceland and the Reykjanes ridge segment $(1,2)$ showing contrasted FRTE concentrations. Individual FRTE ratios do not provide unique solution. In fact, a same FRTE ratio can be explained by a range of modal proportions in the source. However, when combined, FRTE ratios can be used to better constrain the nature of the source.

[1] Eason et al., 2015, Bull. Volcanol., doi:10.1007/s00445015-0916-0

[2] Jenner and O’Neill, 2012, Geochem. Geophys. Geosyst., doi: $10.1029 / 2011 \mathrm{GC} 003890$ 